Research Article

\title{
Chemical Composition and Antioxidant Capacity of Lepidium sativum Seeds from Four Regions of Morocco
}

\author{
Khalid Chatoui, ${ }^{1}$ Hicham Harhar ${ }^{D},{ }^{1}$ Taha El Kamli, ${ }^{2}$ and Mohamed Tabyaoui ${ }^{1}$ \\ ${ }^{1}$ Laboratoire des Matériaux, Nanotechnologies et Environnement (LMNE), Faculté des Sciences, \\ Université Mohammed V de Rabat, BP 1014 Rabat, Morocco \\ ${ }^{2}$ Laboratory of Biological Tests, Food and Nutritional Transition Team (ETAN), Ibn Tofaïl University, Kenitra, Morocco
}

Correspondence should be addressed to Hicham Harhar; hichamoo79@yahoo.fr

Received 3 February 2020; Revised 26 May 2020; Accepted 8 June 2020; Published 30 June 2020

Academic Editor: Victor Kuete

Copyright (c) 2020 Khalid Chatoui et al. This is an open access article distributed under the Creative Commons Attribution License, which permits unrestricted use, distribution, and reproduction in any medium, provided the original work is properly cited.

\begin{abstract}
Lepidium sativum seeds (LSS) from four regions of Morocco have been analyzed for their total chemical composition and antioxidant activities. In the seeds of this plant, the moisture content and yield were, respectively, $9.24-9.88 \%$ and $19.13-19.94 \%$ of dry weight. Chemical analysis of the seeds revealed amounts of fatty acids, sterols, and tocopherols. The most important fatty acids are linolenic acid (33\%) and oleic acid (23\%). The main sterol is $\beta$-sitosterol (50\%); the vegetable oil of Lepidium sativum revealed an amount of tocopherol ( $1500-1900 \mathrm{mg} / \mathrm{kg})$ with dominance of $\gamma$-tocopherol. The Folin-Ciocalteu trial evaluated the total phenolic compound, DPPH radical scavenging, ABTS, and chelated iron ions. FRAP measured antioxidant potency. Results indicated that methanol extract from Lepidium sativum was a more potent reducing agent and radical scavenger than ethanol extract. Changes in the total phenolic content and antioxidant capacity of Lepidium sativum in four different regions grown under normal conditions were evaluated. The antioxidant activity of different extracts was found to correlate significantly with their total phenolic content. These results suggest that Lepidium sativum seeds could be used in food supplement preparations or as a food additive, for caloric gain or for protecting against oxidation in nutrient products.
\end{abstract}

\section{Introduction}

The treatment of diseases from antiquity to the present day has depended in whole or in part on the use of medicinal plants for several reasons, including their action, accessibility, permission, acceptability, and environment [1]. Traditional medicine has a plan for improvement from 2014 to 2023 adapted from the World Health Organization (WHO) [2]. Currently, healing with natural herbal compounds is undergoing a scientific extraction study for screening and chemical identification [3]. Indeed, the medical problems that appear in our body, causing oxidative stress on biomolecules, lead to an imbalance between chemical compounds of plant origin and antioxidants [4]. Among the oxidative, antistress agents that act on reactive species or stimulate the endogenous defence system are vitamins, minerals, phenolic compounds, and carotenoids [5]. The result is a reduction or cessation of diseases such as cerebrovascular risk, diabetes mellitus, arthritis, Parkinson's disease, Alzheimer's disease, and cancer [6].

Morocco has a great diversity of natural and cultivated flora for scientific research in phytotherapy. Thus, some natural products extracted from aromatic herbs and spices are exploited as antioxidants for economic and environmental purposes that could replace the toxic synthetic molecules used recently. This study is based on the seeds of the Lepidium sativum (LSS) plant, also known as garden cress or garden pepper; it is called "Hab rchad" in Morocco. Its seeds contain $27 \%$ protein, $14-26 \%$ fat, $35-54 \%$ carbohydrates, and $8 \%$ crude fiber [7]. Carbohydrates of LSS include $90 \%$ nonstarch polysaccharides and $10 \%$ starch [8]. LSS contain $20-25 \%$ oil, and the main fatty acid is linolenic acid, $32-35 \%$. They also contain natural antioxidants (tocopherols and carotenoids) that help the oil fight rancidity. 
Imidazole alkaloids, lepidine, monomeric alkaloids, sinapic acid, and sinapine are the most important in LSS [9]. It was noted that chemical compounds of plant origin that are studied as secondary metabolite principles are immediately responsible for antioxidant, antimicrobial, antifungal, anticancer, anti-inflammatory, etc. activity [10]. Thus, LSS have been studied as potential bioactive sources, and many of them have shown strong antioxidant capacity and high phenolic levels in some regions of Morocco.

However, studies on the antioxidant and bioactive capacity of LSS compounds are still scarce, especially considering seeds that are grown in different regions of Morocco, with different climates, characteristics, and geographical conditions. The aim of our research is to determine the variability in the chemical substance of vegetable oil, the total phenolic compounds, and the antioxidant capacity (ABTS, DPPH, and FRAP tests) among LSS from four different locations in Morocco.

\section{Materials and Methods}

2.1. Plant Material. The collection of LSS was carried out in four different Moroccan ecosystems (Table 1), the region of Tafraout (TF) located in southwest Morocco, $158 \mathrm{~km}$ from Agadir; El-Haouz (HZ), $44 \mathrm{~km}$ from Marrakech; BenAhmed (BA), $86 \mathrm{~km}$ from Casablanca; and Rommani (RM), $75 \mathrm{~km}$ from Rabat. The seeds were harvested in June 2014. After harvest, the seeds were stored at $4^{\circ} \mathrm{C}$ until their processing.

2.2. Seed Analysis. The percentage by mass of the moisture content of $L S$ seeds is revealed by the AOAC 934.06 technique [11] using an oven (VWR, Sheldon Manufacturing, Inc., Cornelius, Oregon, USA), whose temperature has been kept constant at $103 \pm 2^{\circ} \mathrm{C}$. The oil yield was measured in accordance with DIN EN ISO 659 [12]. Oil extraction was carried out by Soxhlet using hexane as solvent; however, to obtain the alcoholic extracts, the cold maceration method was used, with methanol $(\mathrm{MeOH})$ and ethanol $(\mathrm{EtOH})$ being the two solvents used. All extracted samples were stored at $+4^{\circ} \mathrm{C}$ until use.

The yield is expressed as a percentage and is given by the following formula:

$$
\text { yield }(\%)=\frac{\text { mass of oil }(\text { or dry extract })}{\text { mass of plant material }} \times 100 \text {. }
$$

2.3. Analysis of Seed Oils. The fatty acids were analyzed by gas chromatography according to ISO 5508 [13], and the results were expressed as a relative percentage of each fatty acid present in the sample.

The composition of the sterol was measured according to ISO 6799 [14], while the substance of the tocopherols was determined according to ISO 9936 [15].
TABLE 1: Geographical data of LSS collection sites.

\begin{tabular}{lcccc}
\hline & TF & HZ & BA & RM \\
\hline Altitude $(\mathrm{m})$ & 993 & 500 & 547 & 306 \\
Average temperature $\left({ }^{\circ} \mathrm{C}\right)$ & 16.6 & 19.9 & 17.2 & 17.7 \\
Rainfall $(\mathrm{mm})$ & 235 & 242 & 401 & 436 \\
\hline
\end{tabular}

\subsection{Total Content of Phenols and Flavonoids}

2.4.1. Determination of Total Phenol Content. A mixture of $0.5 \mathrm{~mL}$ of extract solution with $2.5 \mathrm{~mL}$ diluted Folin-Ciocalteu reagent and 1:10 distilled water was made up to $4 \mathrm{~mL}$ of $7.5 \% \mathrm{Na}_{2} \mathrm{CO}_{3}, \mathrm{w} / \mathrm{v}$. This was incubated in a water bath at $45^{\circ} \mathrm{C}$ for 30 minutes, and the OD optical density was read at $765 \mathrm{~nm}$ by the UV-Vis spectrophotometer. The standard gallic acid curve was obtained under the same conditions as above using a range of concentrations. The total phenolic compound was measured in gallic acid equivalents ( $\mu$ g gallic acid equivalent GAE/mg extract) [16].

2.4.2. Determination of Flavonoid Content. 5\% sodium nitrite solution, $0.075 \mathrm{~mL}$, was added to the $0.25 \mathrm{~mL}$ extract solution, to which $1.25 \mathrm{~mL}$ distilled water was added. The mixture was kept for $5 \mathrm{~min}$, and then $0.15 \mathrm{~mL}$ of $10 \%$ aluminum chloride was added for $6 \mathrm{~min}$, and $0.5 \mathrm{~mL}$ of $1 \mathrm{M}$ sodium hydroxide was added. The mixture was diluted with $0.275 \mathrm{~mL}$ distilled water, and the optical density reading was taken at $510 \mathrm{~nm}$ relative to a standard curve prepared by quercetin. The flavonoid content was revealed in quercetin equivalent ( $\mu$ g quercetin equivalent QE/mg extract) [17].

2.4.3. Determination of Tannin Content. The absorbance of a mixture of $500 \mu \mathrm{L}$ of extract solution with $3 \mathrm{~mL}$ of $4 \%$ vanillin-methanol solution and $1.5 \mathrm{~mL}$ hydrochloric acid was measured and left to stand for 15 minutes. The result was given in $\mathrm{mg}$ catechin equivalent ( $\mu \mathrm{g}$ catechin equivalent $\mathrm{CE} /$ mg extract) [18].

\subsection{Antioxidant Activity}

2.5.1. DPPH Free Radical Scavenging Activity. The evaluation of the antioxidant activity of extracts was carried out by the DPPH (1, 1-diphenyl-2-picrylhydrazyl) according to the protocol described by Nounah et al. [19]; a $0.2 \mathrm{mM}$ solution of DPPH was prepared in ethanol, and $0.5 \mathrm{~mL}$ of this solution was added to $2.5 \mathrm{~mL}$ plant extract and left at room temperature for $30 \mathrm{~min}$, after which DO was read at $517 \mathrm{~nm}$ from control samples. The $\mathrm{IC}_{50}$ value is used to express the DPPH results and is defined as the amount of antioxidant required to reduce the radical to $50 \%$. It is inversely related to antioxidant capacity. Lower $\mathrm{IC}_{50}$ values indicate greater effectiveness of the antioxidant power of the extract.

2.5.2. ABTS Radical Scavenging Test. Stock solutions of 7 mM 2,2-azino-bis(3-ethylbenzothiazoline-6-sulfonic acid) (ABTS) and $2.4 \mathrm{mM}$ of potassium persulfate $\mathrm{K}_{2} \mathrm{~S}_{2} \mathrm{O}_{8}$ in equal 
volumes were left in the dark for $12-16 \mathrm{~h}$ at room temperature. Prior to analysis, the ABTS solution was diluted in ethanol to give an OD of $0.7 \pm 0.02$ at $734 \mathrm{~nm}$. $2 \mathrm{~mL}$ of the resulting solutions was allowed to react with $200 \mu \mathrm{l}$ plant extracts at different concentrations, the reaction mixture was vortexed, and the OD was measured at $734 \mathrm{~nm}$ after $30 \mathrm{~min}$. The same procedure was performed for Trolox at different concentrations. The percentage inhibition of $\mathrm{ABTS}^{+}$by the different extracts was measured and evaluated with Trolox. The inhibition concentration parameter $\mathrm{IC}_{50}$ was used to explain the results of the $\mathrm{ABTS}^{\bullet+}$ method. The discoloration of the sample was plotted against the sample concentration to calculate the $\mathrm{IC}_{50}$ value. It is defined as the amount of sample required to reduce the absorbance of the $\mathrm{ABTS}^{\bullet+}$ method by $50 \%$ [19].

\subsubsection{Ferric Reducing Antioxidant Power (FRAP).} Different concentrations of extracts from the stock solution and Trolox standard solution were mixed with $2.5 \mathrm{~mL}$ of phosphate buffer $(0.2 \mathrm{M}, \mathrm{pH} 6.6)$ and $2.5 \mathrm{~mL}$ of potassium ferricyanide $(1 \%, \mathrm{w} / \mathrm{v})$.

The mixture was incubated at $50^{\circ} \mathrm{C}$ for 20 minutes. $2.5 \mathrm{~mL}$ of $10 \% \mathrm{w} / \mathrm{v}$ trichloroacetic acid was added to the reaction mixture. It was then centrifuged at $3000 \mathrm{~g}$ for $10 \mathrm{~min}$. The supernatant of the $2.5 \mathrm{~mL}$ solution was mixed with $2.5 \mathrm{~mL}$ of deionized water and $0.5 \mathrm{~mL}$ of $0.1 \% \mathrm{w} / \mathrm{v}$ ferric chloride. DO was measured at $700 \mathrm{~nm}$ with a reaction time of $30 \mathrm{~min}$. The reducing power of the extracts was represented in Trolox equivalent ( $\mu$ g Trolox equivalent/mg extract) $[20]$.

2.6. Statistical Analysis. The analysis of variance (ANOVA) was performed using IBM SPSS Statistics 21 software to test the statistical significance of Tukey tests at a $95.0 \%$ confidence level, and the results were presented as means \pm standard error of the mean. The Pearson correlation calculation was performed using Microsoft Excel 2010 to estimate the results of the DPPH, ABTS, and FRAP tests obtained for total phenol content (TPC), total flavonoid content (TFC), and total tannin content (TTC).

\section{Results and Discussion}

3.1. Extract Moisture and Yield. The results of this analysis revealed a moisture content of less than $10 \%$ in the different regions of the LSS. The moisture content is almost the same in all four regions: a high moisture content was found in the $\mathrm{TF}$ region, 9.88 \pm 0.03 ; the $\mathrm{HZ}$ and $\mathrm{BA}$ regions have a moisture content of $9.51 \pm 0.04$ and $9.53 \pm 0.10$, respectively; and a moisture content of $9.24 \pm 0.05$ was found in the RM region.

Based on the data recorded in Table 2, the amount of water and volatile matter in the seed exceeds $9 \%$ for all four regions, values higher than those proposed by Brooker and Patterson, 8\%, for oilseed storage [21, 22].

Lipid was obtained by extraction of LSS with hexane using Soxhlet for 8 hours. The results showed that there was no difference in the oil extraction rate. In general, the oil yielded above $19 \%$, with a maximum of about $19.94 \%$ for TF and a minimum of $9.13 \%$ for RM. All these values were lower than those of Diwakar et al. [23] who found that the total oil content of the solvent extracted from $L S$ was $21.54 \%$, and the cold expression was $12.60 \%$. The oil content of LSS is partially lower than that of other edible oilseeds such as mustard (25-40\%), rapeseed (40-45\%), and linseed (40-45\%) of the Cruciferae family [23].

The methanolic $(\mathrm{MeOH})$ and ethanolic $(\mathrm{EtOH})$ extract were obtained by extraction of LSS with methanol and ethanol by hot maceration for 8 hours. The results obtained show a large difference between the yield of $\mathrm{MeOH}$ and $\mathrm{EtOH}$ extract from the four regions. The TF region was significantly higher than the other regions. The content was $31.9 \% \mathrm{MeOH}$ and $21.21 \% \mathrm{EtOH}$. The lowest yield was recorded in the RM region for $\mathrm{MeOH}$ extract, $19.03 \%$, and in the $\mathrm{BA}$ region for EtOH extract, $10.56 \%$.

3.2. Fatty Acid Composition. Table 3 groups the results obtained from oils that are converted to methyl esters and analyzed by gas chromatography on a capillary column of the four regions.

$L S$ oil contains more than $80 \%$ of unsaturated fatty acids, which are composed of major components such as oleic, linolenic, and linoleic acid and a minor compound, palmitoleic acid, less than $0.3 \%$. It also contains saturated fatty acids such as palmitic, stearic, and arachidic acid. The fatty acid composition of $L S$ reported in this study is consistent with previously reported data $[8,23]$.

The main fatty acid of LSS (linolenic acid) is one of the essential fatty acids. It is mainly used to treat hereditary or acquired deficiency of the enzyme $\Delta 6$-desaturase in humans, mainly in the elderly people and in people with stress, diabetes, or alcoholism [24].

Our scientific research conducted at the four stations showed no significant changes in fatty acid levels. The geographical origin therefore does not change the fatty acid composition. These results confirm that climatic conditions have no influence on the fatty acid composition of $L S$ oils from different localities, and are also consistent with the data acquired on the geographical effect on the composition of argan oil [25] and with the study of the effect of geographical origin on the fatty acid composition of olive oils from Italy [26].

3.3. Phytosterol Composition. To determine the impact of geographical origin on the sterol fraction, we opted for a GC analysis that led to the results in Table 4.

The sterol fraction of $L S$ oil is mainly composed of $\beta$-sitosterol and campesterol. As is the case for most vegetable oils, $\beta$-sitosterol was the main phytosterol present in LSS oil. This result is in agreement with the data acquired by Moser et al. [27]. The proportions of $\beta$-sitosterol and campesterol in total sterols vary between 50.17 and $48.17 \%$, and between 22.85 and $24.22 \%$, respectively. These biomolecules provide protection against colon, prostate, and breast cancer [28].

Our results indicate a significant influence $(P<0.05)$ of geographical origin on total sterols in $L S$ oil. It ranged from 
TABLe 2: Raw material characteristics (mean value \pm standard deviation).

\begin{tabular}{lcccc}
\hline & TF & BA & RM & HZ \\
\hline Moisture (\%) & $9.88 \pm 0.03$ & $9.53 \pm 0.10$ & $9.24 \pm 0.05$ & $9.51 \pm 0.04$ \\
Yield (\%) & $19.94 \pm 0.00$ & $19.37 \pm 0.01$ & $19.13 \pm 0.00$ & $19.53 \pm 0.002$ \\
Methanolic extract (\%) & $31.90 \pm 1.14$ & $19.91 \pm 0.54$ & $19.03 \pm 1.18$ & $21.28 \pm 0.80$ \\
Ethanolic extract (\%) & $21.21 \pm 1.01$ & $10.56 \pm 0.55$ & $15.61 \pm 0.66$ & $17.34 \pm 0.67$ \\
\hline
\end{tabular}

TABLE 3: Fatty acid composition (\%) of LSS oil from the four regions studied.

\begin{tabular}{lcccc}
\hline Fatty acid & BA & RM & TF & HZ \\
\hline Myristic C14:0 & $0.10 \pm 0.00^{\mathrm{ab}}$ & $0.10 \pm 0.00^{\mathrm{a}}$ & $0.10 \pm 0.00^{\mathrm{a}}$ & $0.11 \pm 0.00^{\mathrm{b}}$ \\
Palmitic C16:0 & $10.09 \pm 0.35^{\mathrm{a}}$ & $9.98 \pm 0.00^{\mathrm{ab}}$ & $9.86 \pm 0.06^{\mathrm{b}}$ & $9.67 \pm 0.00^{\mathrm{c}}$ \\
Palmitoleic C16:1 & $0.21 \pm 0.00^{\mathrm{a}}$ & $0.20 \pm 0.00^{\mathrm{b}}$ & $0.23 \pm 0.00^{\mathrm{a}}$ & $0.23 \pm 0.00^{\mathrm{a}}$ \\
Stearic C 18:0 & $3.17 \pm 0.03^{\mathrm{a}}$ & $3.32 \pm 0.00^{\mathrm{b}}$ & $3.37 \pm 0.00^{\mathrm{b}}$ & $3.37 \pm 0.00^{\mathrm{b}}$ \\
Oleic C18:1 & $24.08 \pm 0.01^{\mathrm{a}}$ & $23 \pm 0.00^{\mathrm{b}}$ & $23.37 \pm 0.00^{\mathrm{c}}$ & $23.84 \pm 0.00^{\mathrm{d}}$ \\
Linoleic C18:2 & $12.20 \pm 0.05^{\mathrm{ab}}$ & $12.09 \pm 0.00^{\mathrm{a}}$ & $12.19 \pm 0.00^{\mathrm{ab}}$ & $12.27 \pm 0.00^{\mathrm{b}}$ \\
Linolenic C18:3 & $33.65 \pm 0.29^{\mathrm{a}}$ & $33.07 \pm 0.00^{\mathrm{b}}$ & $33.26 \pm 0.00^{\mathrm{c}}$ & $33.57 \pm 0.46^{\mathrm{a}}$ \\
Arachidic C20:0 & $3.34 \pm 0.04^{\mathrm{a}}$ & $3.39 \pm 0.00^{\mathrm{a}}$ & $3.45 \pm 0.00^{\mathrm{a}}$ & $3.72 \pm 0.11^{\mathrm{b}}$ \\
Gadoleic C20:1 & $13.08 \pm 0.02^{\mathrm{a}}$ & $12.29 \pm 0.00^{\mathrm{b}}$ & $12.48 \pm 0.00^{\mathrm{c}}$ & $12.94 \pm 0.00^{\mathrm{d}}$ \\
Saturated fatty acid & 16.72 & 16.79 & 16.72 & 16.87 \\
Unsaturated fatty acid & 83.25 & 80.65 & 81.53 & 82.85 \\
\hline
\end{tabular}

The data are the mean of three replicates $(n=3 \mathrm{e} \pm \mathrm{SEM})$; means followed by similar superscript letters in the same row are not different $(P<0.05)$.

TABLE 4: Sterol composition (\%) of LSS oil in the four regions studied.

\begin{tabular}{lcccc}
\hline Sterol & TF & RM & BA & HZ \\
\hline Cholesterol & $4.00 \pm 0.01^{\mathrm{a}}$ & $2.80 \pm 0.00^{\mathrm{b}}$ & $3.93 \pm 0.00^{\mathrm{c}}$ & $3.99 \pm 0.00^{\mathrm{a}}$ \\
Stigmasterol & $2.49 \pm 0.27^{\mathrm{a}}$ & $2.13 \pm 0.03^{\mathrm{b}}$ & $2.20 \pm 0.00^{\mathrm{b}}$ & $2.40 \pm 0.00^{\mathrm{ab}}$ \\
Campesterol & $24.22 \pm 0.15^{\mathrm{a}}$ & $22.85 \pm 0.00^{\mathrm{b}}$ & $23.79 \pm 0.05^{\mathrm{c}}$ & $24.09 \pm 0.00^{\mathrm{ac}}$ \\
5-Stigmasterol & $4.07 \pm 0.03^{\mathrm{a}}$ & $3.66 \pm 0.02^{\mathrm{b}}$ & $3.60 \pm 0.00^{\mathrm{b}}$ & $3.81 \pm 0.00^{\mathrm{c}}$ \\
$\beta$-Sitosterol & $50.17 \pm 0.03^{\mathrm{a}}$ & $48.17 \pm 0.00^{\mathrm{b}}$ & $12.63 \pm 0.03^{\mathrm{b}}$ & $40.00^{\mathrm{ab}}$ \\
5-Avenasterol & $13.36 \pm 0.32^{\mathrm{a}}$ & $12.21 \pm 0.01^{\mathrm{b}}$ & $0.13 \pm 0.00^{\mathrm{b}}$ & $13.46 \pm 0.26^{\mathrm{c}}$ \\
7-Stigmasterol & $0.30 \pm 0.00^{\mathrm{a}}$ & $0.11 \pm 0.00^{\mathrm{b}}$ & $0.31 \pm 0.00^{\mathrm{c}}$ & $0.36 \pm 0.00^{\mathrm{c}}$ \\
7-Avenasterol & $0.50 \pm 0.01^{\mathrm{a}}$ & $0.20 \pm 0.00^{\mathrm{b}}$ & $95.15 \pm 0.10^{\mathrm{c}}$ & $97.80 \pm 0.48^{\mathrm{d}}$ \\
Total sterol & $99.58 \pm 0.16^{\mathrm{a}}$ & $92.14 \pm 0.04^{\mathrm{b}}$ & & \\
\hline
\end{tabular}

The data are the mean of three replicates $(n=3 \mathrm{e} \pm \mathrm{SEM})$; means followed by similar superscript letters in the same row are not different $(P<0.05)$.

$92.15 \%$ in the RM region to 99.58 in the TF region. Thus, the sterol composition of $L S$ oil is influenced by its origin. This is consistent with the results of Ben Temime et al., who found that geographical origin and climatic factors influence the sterol composition of olive oils [29].

3.4. Tocopherol Content. Analysis of the tocopherol fraction by high-performance liquid chromatography (HPLC) shows a variation of this fraction according to geographical origin. Examination of Table 5 distinguishes essentially four tocopherols, the most important of which is $\gamma$-tocopherol, followed by $\delta$-tocopherol and $\alpha$-tocopherols, while $\beta$-tocopherol is detected only in the $\mathrm{HZ}$ region.

However, the region influences the total tocopherol content, since oils from the $\mathrm{HZ}$ region recorded the highest values, $1940.26 \mathrm{mg} / \mathrm{kg}$, followed by oils from the TF region, $1877.8 \mathrm{mg} / \mathrm{kg}$. Oils from the $\mathrm{BA}$ region recorded the lowest total tocopherol content at $1510.46 \mathrm{mg} / \mathrm{kg}$. All values are higher than those found by Zia-Ul-Haq et al. [30] for the
Pakistani $L S, 1397.3 \mathrm{mg} / \mathrm{kg}$, but comparable to those found by Moser et al. [27]. For comparison, existing crude vegetable base oils with relatively high levels of $\gamma$-tocopherol include corn oil (942 mg/kg), soybean oil (273.3 mg/kg), argan oil (626 mg/kg), and cotton oil (387 ppm) [31-33].

Tocopherols have vitamin $\mathrm{E}$ activity. This vitamin is a powerful antioxidant that captures free radicals and neutralizes destructive oxidation [34]. The main tocopherol in $L S$ oil is $\gamma$-tocopherol, which is a natural antioxidant. The exceptionally high percentage of $\gamma$-tocopherol could make watercress oil a potentially useful industrial source of this natural antioxidant.

3.5. Total Phenols, Flavonoids, and Condensed Tannins. Polyphenols are highly demanded compounds. Plants rich in polyphenolic metabolites have certain biological activities such as antiviral, antithrombotic, anticarcinogenic, antiallergic, antimicrobial, hepatoprotective, and antihypertensive activities [35, 36]. 
TABLE 5: Tocopherol composition (\%) of LSS oil in the four regions studied.

\begin{tabular}{lcccc}
\hline & TF & RM & BA & HZ \\
\hline$\alpha$-tocopherol & $0.78 \pm 0.00^{\mathrm{a}}$ & $1.25 \pm 0.00^{\mathrm{b}}$ & $1.69 \pm 0.012^{\mathrm{c}}$ & $0.39 \pm 0.00^{\mathrm{d}}$ \\
$\beta$-tocopherol & $00 \pm 00^{\mathrm{a}}$ & $00 \pm 00^{\mathrm{a}}$ & $00 \pm 00^{\mathrm{a}}$ & $1.78 \pm 0.00^{\mathrm{b}}$ \\
$\gamma$-tocopherol & $94.48 \pm 0.29^{\mathrm{a}}$ & $94.53 \pm 0.016^{\mathrm{a}}$ & $93.89 \pm 0.01^{\mathrm{ab}}$ & \\
$\delta$-tocopherol & $4.71 \pm 0.04^{\mathrm{a}}$ & $4.18 \pm 0.00^{\mathrm{b}}$ & $4.29 \pm 0.02^{\mathrm{b}}$ & $93.73 \pm 0.06^{\mathrm{b}}$ \\
Total $(\mathrm{mg} / \mathrm{kg})$ & $1877.8 \pm 0.2$ & $1659.9 \pm 0.3$ & $1510.4 \pm 0.2$ & $3.89 \pm 0.01^{\mathrm{c}}$ \\
\hline
\end{tabular}

The data are the mean of three replicates $(n=3 \mathrm{e} \pm \mathrm{SEM})$; means followed by similar superscript letters in the same row are not different $(P<0.05)$.

TABLE 6: Total contents of phenols, flavonoids, and tannins in the $\mathrm{MeOH}$ and $\mathrm{EtOH}$ extract from the four regions studied.

\begin{tabular}{ccccc}
\hline & & Polyphenols (mg GAE/g extract) & Flavonoids $(\mathrm{mg} \mathrm{QE} / \mathrm{g}$ extract) & Tannins (mg CE/g extract) \\
\hline \multirow{2}{*}{$\mathrm{TF}$} & $\mathrm{MeOH}$ & $94.48 \pm 1.82^{\mathrm{a}}$ & $37.63 \pm 2.14^{\mathrm{a}}$ & $26.50 \pm 0.07^{\mathrm{a}}$ \\
& $\mathrm{EtOH}$ & $86.48 \pm 0.22^{\mathrm{b}}$ & $32.51 \pm 0.81^{\mathrm{bc}}$ & $27.79 \pm 0.074^{\mathrm{b}}$ \\
\hline \multirow{2}{*}{$\mathrm{HZ}$} & $\mathrm{MeOH}$ & $83.36 \pm 0.98^{\mathrm{bc}}$ & $33.58 \pm 0.33^{\mathrm{ab}}$ & $25.87 \pm 0.072^{\mathrm{a}}$ \\
& $\mathrm{EtOH}$ & $80.28 \pm 0.28^{\mathrm{c}}$ & $29.24 \pm 0.47^{\mathrm{c}}$ & $26.02 \pm 0.31^{\mathrm{a}}$ \\
\hline \multirow{2}{*}{$\mathrm{BA}$} & $\mathrm{MeOH}$ & $69.46 \pm 0.09^{\mathrm{d}}$ & $24.85 \pm 0.48^{\mathrm{d}}$ & $31.50 \pm 0.11^{\mathrm{c}}$ \\
& $\mathrm{EtOH}$ & $65.15 \pm 1.07^{\mathrm{e}}$ & $23.92 \pm 0.64^{\mathrm{de}}$ & $23.41 \pm 0.25^{\mathrm{d}}$ \\
\hline \multirow{2}{*}{$\mathrm{RM}$} & $\mathrm{MeOH}$ & $59.40 \pm 0.62^{\mathrm{f}}$ & $21.09 \pm 0.21^{\mathrm{de}}$ & $12.85 \pm 0.56^{\mathrm{e}}$ \\
& $\mathrm{EtOH}$ & $52.79 \pm 0.30^{\mathrm{g}}$ & $20.04 \pm 0.04^{\mathrm{e}}$ & $8.33 \pm 0.11^{\mathrm{f}}$ \\
\hline
\end{tabular}

The data are the mean of three replicates $(n=3 \mathrm{e} \pm \mathrm{SEM})$; means followed by similar superscript letters in the same row are not different $(P<0.05)$.

The determinations of total phenols, flavonoids, and tannins were calculated from the linear regression equation of the calibration curve, using gallic acid, quercetin, and catechin as standards, respectively. It can be seen in Table 6 that the total phenol content of the samples ranges from 52.79 to $94.48 \mathrm{mg} \mathrm{GAE} / \mathrm{g}$ extract. Among the studied areas, the TF had the highest phenol content, $94.48 \mathrm{mg}$ GAE/g extract, while the lowest proportion was found in the RM, $52.79 \mathrm{mg}$ GAE/g extract. The considerable difference in phenolic content may be due to environmental factors such as maturity period, climate, location, temperature, productivity, diseases, vegetative part, and environmental aggressiveness [37]. In addition, rainfall continues to affect the phenolic content [38]. A positive correlation is recorded between polyphenol and altitude, while a negative correlation is marked between total phenol and precipitation. Increased phenolic content in plants under water was stressed [39].

Almost all samples were found to be rich in flavonoids. The total flavonoid content ranged from 37.63 in TF to $20.04 \mathrm{mg}$ QE/g extract in RM.

This test shows that the methanolic fraction of the BA contains the highest content of condensed tannins, with a value of $31.50 \mathrm{mg} \mathrm{CE} / \mathrm{g}$ extract. On the other hand, the RM $\mathrm{EtOH}$ fraction recorded the lowest level at $8.33 \mathrm{mg} \mathrm{CE} / \mathrm{g}$ extract. This change is interpreted by the fact that the extraction of condensed tannins depends on the origin of the seeds, the solvent used, and the operating conditions.

3.6. Antioxidant Activity. In this study, the commonly accepted tests DPPH, FRAP, and ABTS were used to assess the antioxidant activity of plant extracts. The results of these tests are presented in Table 7 and are an average of three independent measures.
The antioxidant activity of the different extracts from the four $L S$ regions was determined by calculating the $\mathrm{IC}_{50}$ of the trapping activities of DPPH and ABTS. In parallel, in the FRAP test, the antioxidant activity was determined by calculating the $\mathrm{EC}_{50}$ of the FRAP capacity for each extract. The lower the value of the $\mathrm{IC}_{50}$ or $\mathrm{EC}_{50}$, the higher the antioxidant activity. The DPPH $\mathrm{IC}_{50}, \mathrm{ABTS} \mathrm{IC}_{50}$, and FRAP EC $\mathrm{E}_{50}$ values were compared to the standard ascorbic acid $\mathrm{IC}_{50}$ value. The $\mathrm{IC}_{50}$ values for DPPH and ABTS trapping activities of different extracts from the four regions of the $L S$ were in the range of $119-196.9$ and $187.8-456.8 \mu \mathrm{g} / \mathrm{mL}$, respectively, while the FRAP EC Fo $_{50}$ ranged from 777.0 to $1237.0 \mu \mathrm{g} / \mathrm{mL}$.

The free radical stability of DPPH is observed by OD at $516 \mathrm{~nm}$. The reduction in absorbance of DPPH is related to the antioxidant potential of a sample. The concentration of a sample or standard that can inhibit $50 \%$ of DPPH radical activity is called the $\mathrm{IC}_{50}$ of DPPH scavenging activity. For the positive control ascorbic acid, the results showed that both extracts from the four regions have a very significant antioxidant capacity. We also observed that the extract of $\mathrm{MeOH}$ had a more powerful antioxidant activity than the extract of EtOH, but all these values were very high compared to the standard. A positive correlation was observed between the DPPH and phenolic compounds assay for both $\mathrm{MeOH}$ and $\mathrm{EtOH}$ extracts, and all four locations had a high degree of acceptance $(P<0.05)$. This correlation indicated that the richness in phenolic compounds enhances the antioxidant activity of the plant extract.

The radical cation ABTS was produced in stable form using potassium persulfate. After obtaining the stable absorbance, the antioxidant plant extract was added to the reaction medium, and the antioxidant power was measured by studying discoloration. It should be noted that the TEAC data for all plant species obtained by the ABTS test were higher than those revealed by the DPPH test. 
TABLE 7: $\mathrm{IC}_{50}$ and $\mathrm{EC}_{50}$ values of the effective concentration of the DPPH, ABTS, and FRAP free radical scavenging assays for MeOH and $\mathrm{EtOH}$ extracts from LSS from the four regions.

\begin{tabular}{|c|c|c|c|c|c|c|}
\hline & \multicolumn{2}{|c|}{$\mathrm{DPPH}\left(\mathrm{IC}_{50} \mu \mathrm{g} / \mathrm{mL}\right)$} & \multicolumn{2}{|c|}{ FRAP $\left(\mathrm{EC}_{50} \mu \mathrm{g} / \mathrm{mL}\right)$} & \multicolumn{2}{|c|}{$\operatorname{ABTS}\left(\mathrm{IC}_{50} \mu \mathrm{g} / \mathrm{mL}\right)$} \\
\hline & $\mathrm{MeOH}$ & $\mathrm{EtOH}$ & $\mathrm{MeOH}$ & $\mathrm{EtOH}$ & $\mathrm{MeOH}$ & $\mathrm{EtOH}$ \\
\hline $\mathrm{TF}$ & 119.3 & 134.7 & 777.0 & 813.0 & 187.8 & 211.3 \\
\hline $\mathrm{HZ}$ & 143.3 & 153.8 & 898.0 & 947.0 & 279.0 & 296.5 \\
\hline BA & 162.3 & 177.4 & 980.0 & 1041.0 & 318.7 & 339.1 \\
\hline $\mathrm{RM}$ & 188.0 & 196.9 & 1105.0 & 1237.0 & 345.0 & 456.8 \\
\hline Ascorbic A & \multicolumn{2}{|c|}{17.96} & \multicolumn{2}{|c|}{44.53} & \multicolumn{2}{|c|}{31.47} \\
\hline
\end{tabular}

As shown in Table 7 , the $\mathrm{IC}_{50}$ values for $\mathrm{ABTS}^{\bullet+}$ radical scavenging activity ranged from 187.8 to $456.8 \mu \mathrm{g} / \mathrm{mL}$. By comparing these values with those of the standard, it is evident that the samples tested are effective in their ability to remove the $\mathrm{ABTS}^{\bullet+}$ radical cation at an average concentration.

$L S$ extracts from all four regions showed a high level of significance $(P<0.05)$ between the ABTS $^{\bullet+}$ radical and TPC. The positive and significant correlation between TPC and the antioxidant activity of ABTS reinforces the results observed in the DPPH scavenging method used in this study.

This research is consistent with the hypothesis that an increase in total phenolic compounds will increase the antioxidant activity of extracts, which was previously restored [40].

The FRAP assay measures the reduction potential of an antioxidant that reacts with a ferric tripyridyltriazine complex $\left(\mathrm{Fe}^{3+}-\mathrm{TPTZ}\right)$ to produce a colored ferrous tripyridyltriazine $\left(\mathrm{Fe}^{2+}-\mathrm{TPTZ}\right)$. Breakage of the free radical chain occurs by the donation of a hydrogen atom. At a low $\mathrm{pH}$ of about 3.6, the $\mathrm{Fe}^{3+}$-TPTZ complex reduces to the bluecolored $\mathrm{Fe}^{2+}$-TPTZ, which has an absorbance value at $593 \mathrm{~nm}$.

The results presented in Table 7 showed that the $\mathrm{MeOH}$ extract from the TF region had potent activity, $\mathrm{EC}_{50}=777 \mu \mathrm{g} / \mathrm{mL}$, and standard ascorbic acid, $\mathrm{EC}_{50}=44 \mu \mathrm{g} /$ $\mathrm{mL}$. Therefore, this study showed that high levels of phenolic acid compounds found in the $L S$ are the major contributors to antioxidant activity.

The significant correlation between the FRAP test and total phenolic compounds $\left(r^{2}=0.991\right.$ and $\left.P<0.05\right)$ proves that the high antioxidant activity could be related to the high amount of polyphenols in the extracts, which reinforces the results observed in the DPPH and ABTS methods used in this study.

\section{Conclusion}

In conclusion, our study indicates an influence of geographical origin on the total sterols of Lepidium sativum oil. It ranges from 92.15 in the $\mathrm{RM}$ region to $99.58 \mathrm{mg} / \mathrm{kg}$ in the TF region. The region also influences the total tocopherol content; oils from the $\mathrm{HZ}$ region had the highest values, $1940.26 \mathrm{mg} / \mathrm{kg}$, while oils from the BA region had the lowest total tocopherol content, $1510.46 \mathrm{mg} / \mathrm{kg}$. However, geographical origin does not influence the fatty acid composition. As regards the phenol content, TF had the highest amount (94.48 mg GAE/g extract), while the lowest proportion was found in the RM region $(52.79 \mathrm{mg} \mathrm{GAE} / \mathrm{g}$ extract). The two extracts $\mathrm{MeOH}$ and $\mathrm{EtOH}$ from the four regions had a very significant antioxidant capacity. We also observed that the methanolic extract had more powerful antioxidant activity than the EtOH extract. The LS extracts from the four regions showed a positive and significant correlation between TPC and the antioxidant activity of $\mathrm{DPPH}, \mathrm{ABTS}$, and FRAP.

\section{Data Availability}

All data supporting the findings are adequately included within the article.

\section{Conflicts of Interest}

The authors declare that there are no conflicts of interest regarding the publication of this article.

\section{Acknowledgments}

The authors would like to thank Dr. I. Nounah, C. El Guezzane, and M. Saber for the useful discussion they had throughout the course of this work.

\section{References}

[1] A. F. C. Bolatito, "Antibacterial and phytochemical evaluation of three medicinal plants," Journal of Natural Products, vol. 3 , 2010.

[2] O. Mondiale de la Santé, Stratégie de l'OMS pour la médecine traditionnelle pour 2014-2023, Organisation mondiale de la Santé, Geneva, Switzerland, 2013.

[3] C. Sánchez-Moreno, "Review: methods used to evaluate the free radical scavenging activity in foods and biological systems," Food Science and Technology International, vol. 8, no. 3, pp. 121-137, 2002.

[4] U. Gawlik-Dziki, "Changes in the antioxidant activities of vegetables as a consequence of interactions between active compounds," Journal of Functional Foods, vol. 4, no. 4, pp. 872-882, 2012.

[5] M. M. B. Almeida, P. H. M. de Sousa, Â. M. C. Arriaga et al., "Bioactive compounds and antioxidant activity of fresh exotic fruits from northeastern Brazil," Food Research International, vol. 44, no. 7, pp. 2155-2159, 2011.

[6] F. L. Crowe, A. W. Roddam, T. J. Key et al., "Fruit and vegetable intake and mortality from ischaemic heart disease: results from the European Prospective Investigation into Cancer and Nutrition (EPIC)-Heart study," European Heart Journal, vol. 32, no. 10, pp. 1235-1243, 2011. 
[7] S. Mathews, R. S. Singhal, and P. R. Kulkarni, "Some physicochemical characteristics of Lepidium sativum (haliv) seeds," Food/Nahrung, vol. 37, no. 1, pp. 69-71, 1993.

[8] S. S. Gokavi, N. G. Malleshi, and M. Guo, "Chemical composition of garden cress (Lepidium sativum) seeds and its fractions and use of bran as a functional ingredient," Plant Foods for Human Nutrition, vol. 59, no. 3, pp. 105-111, 2004.

[9] Maier, A Process for the Preparation of Dietary Fibre from Garden Cress Seeds, Science and Education, Indian Patent No. 242/DEL, 2002.

[10] K. Kakate, Practical Pharmacognosy, Vallabh Prakashan, Delhi, India, 4th edition, 1997.

[11] AOAC, Official method of analysis, Association of Official Analytical Chemists, Rockville, MD, USA, 1990.

[12] ISO 659, Oil Seeds-Determination of Oil Content (Reference Method), ISO, Geneva, Switzerland, 2009.

[13] ISO 5508, Animal and Vegetable Fats and Oils Analysis by CPG of Methyl Esters of Fatty Acids, ISO, Geneva, Switzerland, 1990.

[14] ISO 6799, Determination of the sterol fraction by gas chromatography, ISO, Geneva, Switzerland, 1991.

[15] ISO 9936, Animal Fats and Vegetable-Determination of Tocopherols and Tocotrienols by Liquid Chromatography High Performance, ISO, Geneva, Switzerland, 2006.

[16] P. Lister, Measurement of Total Phenolics and ABTS Assay for Antioxidant Activity, Crop Research Institute, Lincoln, New Zealand, 2001.

[17] B. Huang, "Comparative analysis of essential oil components and antioxidant activity of extracts of Nelumbo nucifera from various areas of China," Journal of Agricultural and Food Chemistry, vol. 58, no. 1, pp. 441-448, 2009.

[18] B. Sun, J. M. Ricardo-da-Silva, and I. Spranger, "Critical factors of vanillin assay for catechins and proanthocyanidins," Journal of Agricultural and Food Chemistry, vol. 46, no. 10, pp. 4267-4274, 1998.

[19] I. Nounah, A. Hajib, H. Harhar et al., "Chemical composition and antioxidant activity of Lawsonia inermis seed extracts from Morocco," Natural Product Communications, vol. 12, no. 4, p. 1934578X1701200, 2017.

[20] A. L. Souto, J. F. Tavares, M. S. da Silva, M. d. F. F. M. Diniz, P. F. de Athayde-Filho, and J. M. Barbosa Filho, "Anti-inflammatory activity of alkaloids: an update from 2000 to 2010," Molecules, vol. 16, no. 10, pp. 8515-8534, 2011.

[21] D. B. Brooker, F. W. Bakker-Arkema, and C. W. Hall, Drying and Storage of Grains and Oilseeds, Springer Science \& Business Media, Berlin, Germany, 1992.

[22] H. B. W. Patterson, "Handling and storage of oilseeds, oils, fats, and meal," in Sole Distributor in the USA and Canada, Elsevier Science Pub. Co, Amsterdam, Netherlands, 1989.

[23] B. T. Diwakar, P. K. Dutta, B. R. Lokesh, and K. A. Naidu, "Physicochemical properties of garden cress (Lepidium sativum L.) seed oil," Journal of the American Oil Chemists' Society, vol. 87, no. 5, pp. 539-548, 2010.

[24] D. F. Horrobin, "Nutritional and medical importance of gamma-linolenic acid," Progress in Lipid Research, vol. 31, no. 2, pp. 163-194, 1992.

[25] M. Hilali, Z. Charrouf, A. E. Aziz Soulhi, L. Hachimi, and D. Guillaume, "Influence of origin and extraction method on argan oil physico-chemical characteristics and composition," Journal of Agricultural and Food Chemistry, vol. 53, no. 6, pp. 2081-2087, 2005.

[26] C. Lanza, C. Russo, and F. Tomaselli, "Relationship between geographical origin and fatty acid composition of extra-virgin olive oils produced in three areas of Eastern Sicily," Italian
Journal of Food Science (Italy), vol. 10, no. 4, pp. 359-366, 1998.

[27] B. R. Moser, S. N. Shah, J. K. Winkler-Moser, S. F. Vaughn, and R. L. Evangelista, "Composition and physical properties of cress (Lepidium sativum L.) and field pennycress (Thlaspi arvense L.) oils," Industrial Crops and Products, vol. 30, no. 2, pp. 199-205, 2009.

[28] A. B. Awad, K. C. Chan, A. C. Downie, and C. S. Fink, "Peanuts as a source of $\beta$-sitosterol, a sterol with anticancer properties," Nutrition and Cancer, vol. 36, no. 2, pp. 238-241, 2000.

[29] S. B. Temime, H. Manai, K. Methenni et al., "Sterolic composition of Chétoui virgin olive oil: influence of geographical origin," Food Chemistry, vol. 110, no. 2, pp. 368-374, 2008.

[30] M. Zia-Ul-Haq, S. Ahmad, L. Calani et al., "Compositional study and antioxidant potential of Ipomoea hederacea Jacq. and Lepidium sativum L. seeds," Molecules, vol. 17, no. 9, pp. 10306-10321, 2012.

[31] F. D. Gunstone, Rapeseed and Canola Oil: Production, Processing, Properties and Uses, CRC Press, Boca Raton, FL, USA, 2004.

[32] E. N. Frankel, Lipid Oxidation, The Oily Press, Bridgewater, MA, USA, 2005.

[33] H. Harhar, S. Gharby, B. Kartah, H. El Monfalouti, D. Guillaume, and Z. Charrouf, "Influence of argan kernel roasting-time on virgin argan oil composition and oxidative stability," Plant Foods for Human Nutrition, vol. 66, no. 2, pp. 163-168, 2011.

[34] J. B. Rossell and J. Pritchard, Analysis of Oilseeds, Fats and Fatty Foods, Elsevier Science Publishers Ltd, Amsterdam, Netherlands, 1991.

[35] M. Riaz, "In vitro antioxidant potential of selected aphrodisiac medicinal plants," Journal of Biological Regulators and Homeostatic Agents, vol. 31, no. 2, pp. 419-424, 2017.

[36] A. Kauser, "In vitro antioxidant and cytotoxic potential of methanolic extracts of selected indigenous medicinal plants," Progress in Nutrition, vol. 20, pp. 706-712, 2018.

[37] D. Jackson and P. Lombard, "Environmental and management practices affecting grape composition and wine quality-a review," American Journal of Enology and Viticulture, vol. 44, no. 4, pp. 409-430, 1993.

[38] M. Das and A. Pal, "In vitro regeneration of Bambusa balcooa Roxb.: factors affecting changes of morphogenetic competence in the axillary buds," Plant Cell, Tissue and Organ Culture, vol. 81, no. 1, pp. 109-112, 2005.

[39] I. N. De Abreu and P. Mazzafera, "Effect of water and temperature stress on the content of active constituents of Hypericum brasiliense Choisy," Plant Physiology and Biochemistry, vol. 43, no. 3, pp. 241-248, 2005.

[40] S. Bakari, M. Ncir, S. Felhi et al., "Chemical composition and in vitro evaluation of total phenolic, flavonoid, and antioxidant properties of essential oil and solvent extract from the aerial parts of Teucrium polium grown in Tunisia," Food Science and Biotechnology, vol. 24, no. 6, pp. 1943-1949, 2015. 